\author{
Stephan Ehrmann \\ Ferran Roche-Campo \\ Laetitia Bodet-Contentin \\ Keyvan Razazi \\ Jonathan Dugernier \\ Josep Trenado-Alvarez \\ Alexis Donzeau \\ François Vermeulen \\ David Thévoz \\ Metaxia Papanikolaou \\ Antoine Edelson \\ Héctor León Yoshido \\ Lise Piquilloud \\ Karim Lakhal \\ Carlos Lopes \\ Carlos Vicent \\ Arnaud Desachy \\ Gabriela Apiou-Sbirlea \\ Daniel Isabey \\ Laurent Brochard \\ Reva Research Network \\ AT@ICU Study Group
}

Received: 7 August 2015

Accepted: 18 October 2015

Published online: 24 November 2015

(C) Springer-Verlag Berlin Heidelberg and ESICM 2015

Take-home message: Aerosol therapy concerns every fourth critically ill patient and every fifth ventilated patient. Implementation modalities appeared heterogeneous and suboptimal in a significant number of cases calling for action on the educational level to improve knowledge translation from research to clinical practice.

The investigators/contributors of the centers participating in the AT@ICU study group are listed in the Acknowledgments.

Electronic supplementary material The online version of this article (doi:10.1007/s00134-015-4114-5) contains supplementary material, which is available to authorized users.

S. Ehrmann · G. Apiou-Sbirlea · D. Isabey Institut National de la Santé et de la Recherche Médicale, UMR 955 and Centre National de la Recherche Scientifique, ERL 7240, Equipe de Biomécanique Cellulaire et Respiratoire, Université Paris Est, Créteil, France

\title{
Aerosol therapy in intensive and intermediate care units: prospective observation of 2808 critically ill patients
}

S. Ehrmann $(\varpi) \cdot$ L. Bodet-Contentin Réanimation Polyvalente, Centre Hospitalier Régional et Universitaire de Tours, F37044 Tours Cedex 9, France e-mail: stephanehrmann@gmail.com Tel.: +33 (0)6 71103302

\section{S. Ehrmann}

Institut National de la Santé et de la Recherche Médicale, Centre d'Étude des Pathologies Respiratoires, UMR 1100, Aérosolthérapie et Biomédicaments à Visée Respiratoire, Faculté de Medecine, Université François Rabelais, Tours, France

\section{F. Roche-Campo}

Medicina Intensiva, Hospital Verge de la Cinta, Tortosa, Tarragona, Spain

\section{Bodet-Contentin}

Réanimation Médicale, Hôpital Cochin, Assistance Publique-Hôpitaux de Paris and Faculté de Médecine, Université Paris Descartes, Sorbonne Paris Cité, Paris, France

\section{K. Razazi}

Assistance Publique-Hôpitaux de Paris, GHU Henri Mondor, DHU A-TVB, Service de Réanimation Médicale, Groupe de Recherche CARMAS, Créteil, France

\section{J. Dugernier}

Intensive Care Unit, Cliniques

Universitaires Saint-Luc, Brussels, Belgium

J. Trenado-Alvarez

Servei Medicina Intensiva, Hospital

Universitari Mutua Terrassa, Universitat de Barcelona, Terrassa, Barcelona, Spain

A. Donzeau · L. Piquilloud Réanimation Médicale et Médecine Hyperbare, Centre Hospitalier Régional Universitaire d'Angers, Angers, France

\section{F. Vermeulen}

Department of Intensive Care, Hôpitaux Universitaires de Genève, Rue GabriellePerret-Gentil 4, 1211 Geneva, Switzerland

D. Thévoz · L. Piquilloud Médecine Intensive Adulte et Centre des Brulés, Centre Hospitalier Universitaire Vaudois, Lausanne, Switzerland

M. Papanikolaou Intensive Care Unit, Hippocrateion General Hospital of Athens, Athens, Greece

\section{A. Edelson}

Réanimation, Centre Hospitalier du Taaone, Pirae, French Polynesia 
H. León Yoshido

Medicina Intensiva, Hospital Nacional

Edgardo Rebagliati Martins Essalud, Lima, Peru

\section{K. Lakhal}

Réanimation Chirurgicale Polyvalente, Service d'Anesthésie-Réanimation, Hôpital Laënnec, Centre Hospitalier Régional Universitaire de Nantes, F44093 Nantes, France

C. Lopes

UCIR-Pulmonology, Hospital de Santa

Maria, CHLN, Lisbon, Portugal

C. Vicent

Intensive Care Unit, Hospital Lluis

Alcanyis, Xativa, Valencia, Spain

A. Desachy

Service de Réanimation, Centre Hospitalier d'Angoulême, Angoulême, France

G. Apiou-Sbirlea

Department of Dermatology, Harvard Medical School, Wellman Center for Photomedicine, Massachusetts General Hospital, Boston, USA

L. Brochard

Keenan Research Centre, Li Ka Shing

Knowledge Institute, St Michael's Hospital,

Toronto, Canada

L. Brochard

Interdepartmental Division of Critical Care Medicine, University of Toronto, Toronto, Canada
Reva Research Network

Angers, France

AT@ICU Study Group

Tours, France

Abstract Purpose: Unlike in the outpatient setting, delivery of aerosols to critically ill patients may be considered complex, particularly in ventilated patients, and benefits remain to be proven. Many factors influence aerosol delivery and recommendations exist, but little is known about knowledge translation into clinical practice. Meth-

ods: Two-week cross-sectional study to assess the prevalence of aerosol therapy in 81 intensive and intermediate care units in 22 countries. All aerosols delivered to patients breathing spontaneously, ventilated invasively or noninvasively (NIV) were recorded, and drugs, devices, ventilator settings, circuit set-up, humidification and side effects were noted. Results: A total of 9714 aerosols were administered to 678 of the 2808 admitted patients (24\%, $\mathrm{CI}_{95}$ 22-26\%), whereas only 271 patients $(10 \%)$ were taking inhaled medication before admission. There were large variations among centers, from 0 to $57 \%$. Among intubated patients $22 \%(n=262)$ received aerosols, and $50 \%(n=149)$ of patients undergoing NIV, predominantly $(75 \%)$ inbetween NIV sessions. Bronchodilators $(n=7960)$ and corticosteroids ( $n=1233)$ were the most frequently delivered drugs (88\% overall), predominantly but not exclusively (49\%) administered to patients with chronic airway disease. An anti-infectious drug was aerosolized 509 times (5\% of all aerosols) for nosocomial infections. Jet-nebulizers were the most frequently used device (56\%), followed by metered dose inhalers $(23 \%)$. Only $106(<1 \%)$ mild side effects were observed, despite frequent suboptimal set-ups such as an external gas supply of jet nebulizers for intubated patients.

Conclusions: Aerosol therapy concerns every fourth critically ill patient and one-fifth of ventilated patients.

Keywords Administration, inhalation $[\mathrm{MeSH}]$.

Metered dose inhalers [MeSH] . Nebulizers and vaporizers [MeSH] . Bronchodilator agents [MeSH] • Anti-bacterial agents [MeSH] . Respiration, artificial [MeSH]

\section{Introduction}

Aerosol therapy, i.e., the delivery of medication particles carried by inhaled gases, constitutes the cornerstone of chronic broncho-dilatory and anti-inflammatory therapy for patients suffering from asthma and chronic obstructive pulmonary disease. It is associated with improved longterm patient-centered outcomes [1-3]. Similarly, antibiotic aerosol therapy has proven effective to treat lung infection in patients suffering from cystic fibrosis [4].

In the acute setting, particularly in the critically ill patients, evaluation of patient-centered outcomes is lacking. Nevertheless, a large body of work has evaluated optimal implementation of aerosol therapy in patients undergoing artificial ventilation in terms of practicability and safety, and has shown significant physiologic efficacy of several inhaled drugs in this setting [5-11]. Significant reductions in respiratory system resistance of ventilated patients have been demonstrated after delivery of bronchodilator using various nebulizer and metered dose inhaler (MDI) set-ups [6, 12, 13]. In ventilator-associated pneumonia, optimized nebulization set-ups such as a low inspiratory peak flow, increased inspiratory time, interrupted humidification and nebulizer placement upstream in the inspiratory limb seem to deliver inhaled antibiotics effectively to treat lung infections [14-17]. Large-scale international studies on ventilatory support have not recorded data about aerosol therapy $[18,19]$. In a previous study using an e-mail self-administered survey, we obtained responses from 854 physicians who declared being confident in aerosol therapy efficacy and using it frequently in critically ill patients [20]. In this previous study, knowledge appeared very heterogeneous [20]. A Scandinavian observational study reported the use of aerosol therapy in $50 \%$ of 186 ventilated patients (mainly beta-2-adrenergic receptor agonists), without providing data about implementation modalities [21]. This lack of large-scale prospective data hampers optimal knowledge 
translation towards the clinical setting and optimal research and educational resources allocation. The aim of the present work was to assess the frequency, modalities and short-term safety of aerosol therapy in critically ill patients either breathing spontaneously or undergoing invasive or noninvasive (NIV) artificial ventilation.

\section{Methods}

This prospective cross-sectional point prevalence study was carried out over 14 days in 81 intensive care units in 22 countries (see the list of centers and investigators in the Appendix). Centers were recruited on a voluntary basis among participants of the aforementioned e-mail survey by purposive sampling through e-mail contact of members of the European Society of Intensive Care Medicine, French and Spanish intensive care societies (Société de Réanimation de Langue Française, Revista Electrónica de Medicina Intensiva) and members of the REVA network (Réseau Européen de recherche en Ventilation Artificielle) [20]. The study was approved by the ethics commission of the French intensive care society and additional ethical approval gained at each participating institution if legally required. Given the noninterventional study design, the need for written informed consent was waived by those independent commissions. All patients or their next of kin were informed about the study with the possibility to decline participation. The 2-week participation periods for each unit were staggered over March and April 2013.

All patients present in the unit during the study period and not declining participation were included. Each day, patients' ventilator statuses were prospectively recorded: (1) "invasive artificial ventilation": patient breathing or ventilated through a tracheal tube or tracheostomy; (2) "NIV": patient who underwent at least one NIV session (including continuous positive airway pressure) but no "invasive artificial ventilation"; and (3) "spontaneous breathing" otherwise. Each time a patient received inhaled medication during the study period (aerosol therapy, but also instillation of drugs in the tracheal tube, except $0.9 \%$ sodium chloride instillation for tracheal suctioning), extensive data were recorded (see electronic supplement Tables 1, 2 and 3 for an extensive list of recorded variables). Investigators were invited to report any significant adverse event without specific a priori definition.

Data were entered into a web-based database (ClinInfo, Lyon, France) and analyses performed using $\mathrm{R}$ 2.14.1 (R Foundation for Statistical Computing, Vienna, Austria). Quantitative variables were expressed as mean \pm standard deviation and compared with Student's $t$ test, except in cases of non-Gaussian distribution [median (25th, 75th percentile)]. Qualitative variables were expressed as counts (\%) and compared between groups using the Chi-square test. The $95 \%$ confidence interval $\left(\mathrm{CI}_{95}\right)$ of proportions was calculated for the main variables of aerosol therapy (no missing value, no data imputation). A $p$ value lower than 0.05 was considered significant.

\section{Results}

A total of 2808 patients were included (Table 1), predominantly in intensive care units $[10,689(81 \%)$ vs. $2514(19 \%)$ patient-days in intermediate care], and 9714 inhaled drug administrations were recorded. Follow-up was complete; participating countries and centers are detailed in the electronic supplement (Table 4).

\section{Frequency of aerosol therapy}

A total of 678 patients $\left(24 \% \mathrm{CI}_{95} 22-26 \%\right.$ ) received at least one inhaled medication over the 2 -week period [median number of $7(2,18)$ per patient], while only 271 patients $(10 \%)$ were taking inhaled medications chronically at home. Frequency of aerosol therapy was heterogeneous between centers (range $0-57 \%$ of patients; see electronic supplement Table 4). Aerosolgenerating devices and patients' ventilation status during aerosol therapy are detailed in Table 2. Overall, aerosols were mainly delivered either to patients breathing spontaneously $(n=4832$ aerosols, $50 \%)$ or into the ventilator circuit of intubated patients $(n=4532,47 \%)$, representing two distinct clinical and therapeutic situations. Aerosols under NIV represented only $3 \%$ of all aerosols.

Spontaneously breathing patients

Among 4832 aerosols performed in patients breathing spontaneously, jet nebulizers were used predominantly $(n=3388,70 \%)$, followed by MDIs $(n=790,16 \%)$.

\section{NIV}

Among 305 patients who underwent one or several days of NIV, 149 (49 \% $\mathrm{CI}_{95} 40-57 \%$ ) received at least one aerosol on such days. Aerosols were predominantly delivered when patients were breathing spontaneously inbetween NIV sessions $(n=1057$ aerosols, i.e. $75 \%$ of aerosols in patients undergoing NIV) and infrequently directly into the ventilatory circuit $(n=350$ aerosols, i.e. $25 \%$ of aerosols in patients undergoing NIV). Among 
Table 1 Characteristics of patients receiving or not aerosol therapy

\begin{tabular}{|c|c|c|c|}
\hline & $\begin{array}{l}\text { All patients } \\
n=2808\end{array}$ & $\begin{array}{l}\text { Patients who received aerosols } \\
n=678\end{array}$ & $\begin{array}{l}\text { Other patients } \\
n=2130\end{array}$ \\
\hline Age (years) & $59 \pm 21$ & $61 \pm 19$ & $58 \pm 21$ \\
\hline Male/female & $1713(61 \%) / 1095(39 \%)$ & $429(63 \%) / 249(37 \%)$ & $1284(60 \%) / 846(40 \%)$ \\
\hline $\begin{array}{l}\text { Simplified acute physiology score II } \\
\text { Type of admission }\end{array}$ & $38 \pm 19$ & $40 \pm 16$ & $37 \pm 20$ \\
\hline Medical & $1918(73 \%)$ & $531(78 \%)$ & $1385(65 \%)$ \\
\hline Scheduled surgery & $381(14 \%)$ & $48(7 \%)$ & $333(16 \%)$ \\
\hline Emergency surgery & $335(13 \%)$ & $61(9 \%)$ & $274(13 \%)$ \\
\hline History of cardiovascular disease & $939(33 \%)$ & $244(36 \%)$ & $695(33 \%)$ \\
\hline History of respiratory disease & $673(24 \%)$ & $371(55 \%)$ & $302(14 \%)$ \\
\hline Chronic obstructive pulmonary disease & $486(17 \%)$ & $287(42 \%)$ & $199(9 \%)$ \\
\hline Chronic restrictive pulmonary disease & $135(5 \%)$ & $66(10 \%)$ & $69(3 \%)$ \\
\hline Pulmonary arterial hypertension & $68(2 \%)$ & $29(4 \%)$ & $39(2 \%)$ \\
\hline Asthma & $95(3 \%)$ & $58(8 \%)$ & $37(2 \%)$ \\
\hline Chronic use of inhaled medication & $271(10 \%)$ & $176(26 \%)$ & $95(4 \%)$ \\
\hline \multicolumn{4}{|l|}{ Main admission diagnosis } \\
\hline Shock & $404(14 \%)$ & $87(13 \%)$ & $317(15 \%)$ \\
\hline Severe sepsis & $120(4 \%)$ & $26(4 \%)$ & $94(4 \%)$ \\
\hline Acute respiratory failure & $675(24 \%)$ & $333(49 \%)$ & $342(16 \%)$ \\
\hline De novo & $378(56 \%)$ & $132(40 \%)$ & $246(72 \%)$ \\
\hline Exacerbation of chronic respiratory failure & $297(44 \%)$ & $201(60 \%)$ & $96(28 \%)$ \\
\hline Coma/seizure & $268(9 \%)$ & $42(6 \%)$ & $226(11 \%)$ \\
\hline Cardiac arrest & $106(4 \%)$ & $17(3 \%)$ & $89(4 \%)$ \\
\hline Monitoring & $690(25 \%)$ & $85(13 \%)$ & $605(28 \%)$ \\
\hline Post-operative & $542(78 \%)$ & $71(84 \%)$ & $471(78 \%)$ \\
\hline Medical monitoring & $148(21 \%)$ & $14(16 \%)$ & $134(22 \%)$ \\
\hline Other & $665(24 \%)$ & $114(17 \%)$ & $551(26 \%)$ \\
\hline
\end{tabular}

${ }^{a}$ Defined according to the simplified acute physiology score II aerosol and patients never receiving aerosols were statistically [22]. Data are presented as mean \pm standard deviation and count significant except for gender and history of cardiovascular disease

(\%). All comparisons between patients who received at least one

Table 2 Characteristics of aerosols

\begin{tabular}{lc}
\hline & $n=9714$ \\
\hline Aerosol generation devices & \\
Jet nebulizer & $5436(56 \%)$ \\
Ultrasonic nebulizer $^{\text {Vibrating mesh nebulizer }}$ & $940(10 \%)$ \\
Hand held devices $^{\mathrm{a}}$ & $999(10 \%)$ \\
Instillation $^{\mathrm{b}}$ & $2216(23 \%)$ \\
Ventilation during aerosol delivery $^{\text {Spontaneous breathing }}$ & $123(1 \%)$ \\
NIV $^{\mathrm{c}}$ & \\
Invasive ventilation $^{\text {Number of molecules within one aerosol }}{ }^{\mathrm{d}}$ & $4832(50 \%)$ \\
1 & $350(4 \%)$ \\
2 & $4532(47 \%)$ \\
$\geq 3$ & $5583(57 \%)$ \\
\hline
\end{tabular}

Data are presented as count $(\%)$

MDI metered dose inhaler

${ }^{a}$ Metered dose inhalers only in ventilated patients, metered dose inhalers and dry powder inhalers in spontaneous breathing

b Only instillations other than $0.9 \%$ sodium chloride used for tracheal suctioning were recorded

c Aerosol delivered within the non-invasive ventilation (NIV) circuit

${ }^{\mathrm{d}} 0.9 \%$ sodium chloride was not considered as an additional drug when being used as a solvent for another molecule
1057 aerosols delivered inbetween NIV sessions, only 171 aerosols (16\%) specifically triggered NIV interruption in order to deliver the inhaled therapy.

\section{Intubated patients}

Among 1215 patients who underwent invasive artificial ventilation, $262\left(22 \% \mathrm{CI}_{95} 20-24 \%\right)$ received at least one aerosol while intubated. Aerosols delivered during artificial ventilation were mostly delivered in patients intubated and ventilated with a two-limb ventilatory circuit $(n=4499,92 \%)$ (Fig. 1; Table 3$)$. Bronchodilators and corticosteroids were mainly delivered using nebulizers ( $n=2264$ bronchodilator aerosols, $63 \% ; n=355$ corticosteroid aerosols, $69 \%$ ). In intubated patients, antibiotics were delivered using jet, ultrasonic and vibrating mesh nebulizers in 221 (62\%), 105 (29\%) and $31(9 \%)$ cases, respectively. Ventilator settings were changed for administration of 107 anti-infectious aerosols $(30 \%)$ as compared to only $74(2 \%)$ of bronchodilator aerosols $(p<0.01)$. Similarly, when using a heated humidifier, the device was turned off for 119 (59\%) antiinfectious aerosols as compared to 249 (15\%) of 
bronchodilator aerosols $(p<0.01)$. Placement of the nebulizer upstream in the inspiratory $\operatorname{limb}$ at a distance from the $\mathrm{Y}$ piece remained infrequent even for administration of anti-infectious aerosols $(n=33,9 \%$ of antiinfectious aerosols) (Fig. 1). Among 1867 aerosols delivered using a jet nebulizer, a ventilator integrated breath-actuated jet nebulization system was available in 1115 cases $(60 \%)$; when available, it was used for nearly all cases $(n=1109,99 \%)$. Placement of a filter on the expiratory limb to protect the ventilator was done for 2997 (66 \%) aerosol administrations; this filter was infrequently changed in relation to nebulization (Fig. 1).

\section{Drugs delivered}

Drugs were frequently delivered as a combination ( $n=4131$ aerosols, $42 \%$; Table 2$)$. This mainly concerned association of a short acting beta-2-adrenergic agonist and an anticholinergic drug $(n=2317,56 \%$ of combined aerosols). Bronchodilators $(n=7960$ aerosols) represented $82 \%$ of administrations and concerned $89 \%$ of patients receiving aerosols (Table 4). Corticosteroids were the second most frequent inhaled drugs $(n=1233$, i.e. $13 \%$ of aerosols and $26 \%$ of patients receiving aerosols). Together, bronchodilators and corticosteroids represented $88 \%$ of aerosols. These drugs were delivered far beyond the patients suffering chronic obstructive pulmonary diseases or asthma, who accounted for 312 patients among the 626 receiving bronchodilators and/or corticosteroids $(50 \%)$. Indeed, in a majority of cases, bronchodilator and corticosteroid aerosols were delivered to treat exacerbation of COPD, acute asthma or acute bronchospasm of another origin $(n=2204,51 \%$ of aerosols with only one molecule), but various other heterogeneous indications were observed such as infection $(n=579,13 \%)$ or wheezing of undetermined origin ( $n=293,7 \%$ ) (see Table 5 of the electronic supplement).

A total of 509 anti-infectious aerosols were recorded, predominantly colistin $(n=400,79 \%$ of anti-infectious aerosols) and amikacin $(n=49,10 \%)$. Anti-infectious aerosols were primarily indicated to treat nosocomial pneumonia $(n=342,67 \%)$ and to a lesser extent tracheobronchitis/bronchial colonization $(n=94,19 \%)$. Prophylactic anti-infectious aerosols accounted for a smaller proportion $(n=31,6 \%)$. Overall, anti-infectious

Table 3 Aerosol therapy in intubated patients

Observed practice Recommendations for optimal efficacy/safety

$n=4532$

\begin{tabular}{|c|c|c|}
\hline \multicolumn{3}{|l|}{ Aerosol generating devices } \\
\hline Jet nebulizer & $1867(42 \%)$ & \\
\hline $\begin{array}{l}\text { Use of ventilator integrated breath-actuated } \\
\text { system if available }\end{array}$ & $1109(99 \%)$ & To be preferred if use of a jet-nebulizer \\
\hline No integrated breath-actuated system available & $752(40 \%)$ & \\
\hline Ultrasonic nebulizer & $790(17 \%)$ & \\
\hline Vibrating mesh nebulizer & $495(11 \%)$ & \\
\hline MDI & $1331(29 \%)$ & Metered dose inhaler to be preferred if drug available \\
\hline $\begin{array}{l}\text { Use of a ventilator circuit access port/circuit } \\
\text { disconnection }\end{array}$ & $1283(96 \%) / 48(4 \%)$ & Avoid circuit disconnection \\
\hline Use of an inhalation chamber & $359(27 \%)$ & Prefer use of a chamber \\
\hline Position & & \\
\hline Close to the Y piece & & May induce expiratory loss of drug \\
\hline Immediately downstream/immediately upstream & $1850(51 \%) / 1789(49 \%)$ & \\
\hline At distance of the Y piece & $748(16 \%)$ & Upstream position improves delivery \\
\hline $\begin{array}{l}\text { Upstream in the inspiratory limb, using an extra } \\
\text { connection tubing }\end{array}$ & $707(94 \%)$ & \\
\hline At the ventilator output & $41(5 \%)$ & \\
\hline Other & $145(3 \%)$ & \\
\hline Heated humidifier interrupted (if used) & $373(18 \%)$ & Interruption may improve aerosol delivery \\
\hline Use of a protective filter on the expiratory limb 2 & $2997(66 \%)$ & Filter to be used to avoid expiratory block dysfunction, to \\
\hline Filter changed several times during nebulization & $72(2 \%)$ & be changed to avoid filter obstruction \\
\hline Filter changed at the end of nebulization & \multirow{2}{*}{$\begin{array}{r}287(10 \%) \\
2638(88 \%)\end{array}$} & \\
\hline Filter not changed in relation with nebulization & & \\
\hline $\begin{array}{l}\text { Connection tubing between Y piece and tracheal } \\
\text { tube removed/left in place (if used) }\end{array}$ & $140(4 \%) / 3750(96 \%)$ & Connection tubing may reduce aerosol delivery \\
\hline \multicolumn{3}{|c|}{ 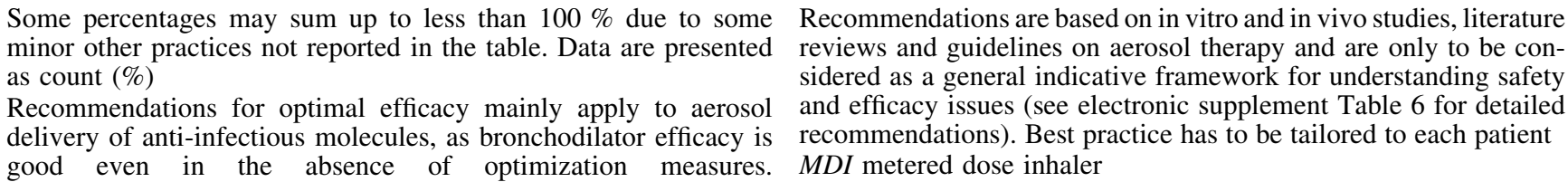 } \\
\hline
\end{tabular}



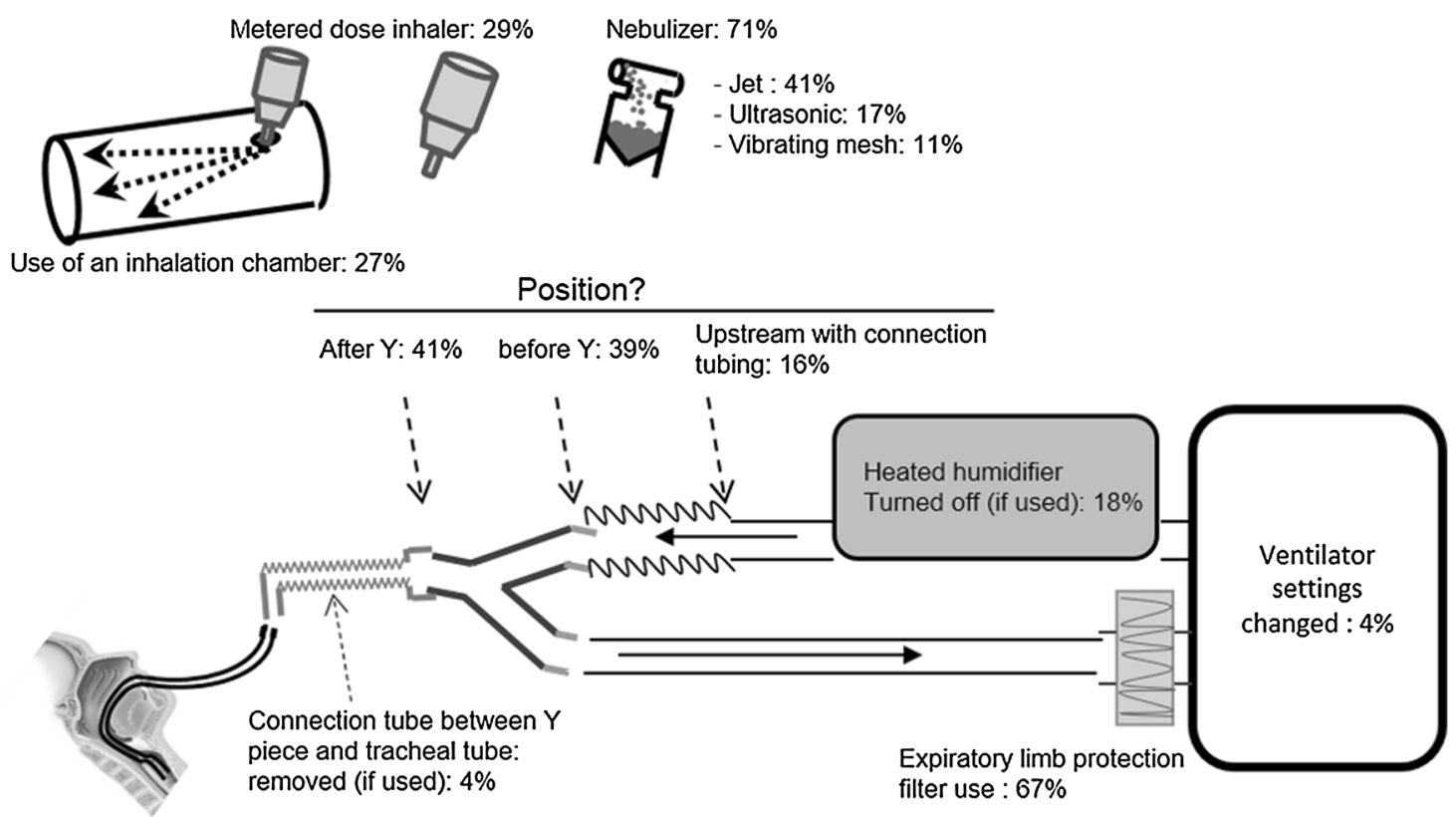

Fig. 1 Main determinants of aerosol set-ups used in intubated patients. In intubated patients, aerosol therapy was predominantly performed using jet nebulizers placed close to the $\mathrm{Y}$ piece while ventilator settings were left unchanged

aerosols concerned 31 patients $(1 \%)$ in 14 centers $(17 \%)$.

\section{Side effects}

A total of 106 administrations $(<1 \%)$ prompted notification of a side effect, mainly tachycardia and arterial hypertension $(n=39)$, arterial hypotension $(n=16)$, hypoxemia $(n=20)$ and cough $(n=23)$. Bronchospasm was reported three times (colistin nebulization in all cases).

\section{Discussion}

The main results of this large-scale prospective international cross-sectional prevalence study is that aerosol therapy is used in one-fourth of critically ill patients and in every fifth intubated patient, confirming smaller-scale observations and declarative data $[20,21]$. Aerosol therapy appeared even more frequent in patients undergoing NIV, as half of those patients received aerosols, mainly inbetween ventilation sessions. Bronchodilators and corticosteroids were the overwhelmingly predominant drugs delivered as aerosols (88 \%); anti-infectious aerosols, even though representing a smaller proportion of aerosols (5\%), were frequently recorded over the 14-day study period and almost exclusively delivered to treat nosocomial infections; only $3 \%$ of aerosols were mucusmodulating drugs. Albeit only a limited number of side effects were recorded in the present study, the high prevalence of aerosol therapy observed raises questions about the optimization of technical implementation and long-term safety in the critical care setting.

\section{Spontaneous breathing}

The predominant use of nebulizers to deliver aerosols in critically ill patients is in accordance with guidelines addressing aerosol therapy for severe asthma and chronic obstructive pulmonary disease exacerbation in the emergency department as proper use of MDIs may be difficult for those patients [11].

\section{NIV}

Interestingly, about a quarter of aerosols delivered to patients breathing spontaneously concerned patients otherwise undergoing NIV. This may suggest poor knowledge translation given existing data on the efficacy of inhaled bronchodilators delivered within NIV circuits [23-26]. Conversely, one may hypothesize that clinicians and nursing staff consider aerosol delivery into ventilator circuits too cumbersome, thus calling for progress in equipment simplification.

\section{Intubated patients}

Safety and efficacy issues may be discussed based on the current literature (briefly summarized in the electronic 
Table 4 Drugs delivered as aerosols

\begin{tabular}{lcc}
\hline & Aerosols $(n=9714)$ & Patients $(n=678)$ \\
\hline Bronchodilators & $7960(82 \%)$ & $600(89 \%)$ \\
Short acting beta-2-adrenergic agonists & $6780(95 \%)$ & $463(86 \%)$ \\
Long acting beta-2-adrenergic agonists & $88(1 \%)$ & $24 \%)$ \\
Anticholinergic drugs & $4958(70 \%)$ & $198(37 \%)$ \\
Corticosteroids & $1233(13 \%)$ & $173(26 \%)$ \\
Beclomethasone dipropionate & $269(22 \%)$ & $31(18 \%)$ \\
Budesonide & $897(74 \%)$ & $130(77 \%)$ \\
Fluticasone & $60(5 \%)$ & $11(6 \%)$ \\
Other & $5(<1 \%)$ & $1(<1 \%)$ \\
Anti-infectious drugs & $509(5 \%)$ & $31(5 \%)$ \\
Amikacin & $31(6 \%)$ & $9(30 \%)$ \\
Amphotericin B & $33(6 \%)$ & $4(13 \%)$ \\
Colistin & $400(79 \%)$ & $19(63 \%)$ \\
Gentamicin & $21(4 \%)$ & $2(7 \%)$ \\
Ceftazidime & $6(1 \%)$ & $3(10 \%)$ \\
Tobramycin & $14(4 \%)$ & $2(<1 \%)$ \\
Mucus modulating drugs & $241(3 \%)$ & $39(6 \%)$ \\
Acetylcysteine & $136(61 \%)$ & $22(65 \%)$ \\
Recombinant human deoxyribonuclease & $12(5 \%)$ & $7(21 \%)$ \\
2-Mercapto ethane sodium sulfonate (Mesna) & $93(42 \%)$ & $11(32 \%)$ \\
Electrolyte solutions & $503(5 \%)$ & $71(9 \%)$ \\
0.9\% sodium chloride & $440(87 \%)$ & $65(91 \%)$ \\
Hypertonic sodium chloride & $16(3 \%)$ & $2(3 \%)$ \\
Sodium bicarbonate & $47(9 \%)$ & $4(6 \%)$ \\
Other & $14(<1 \%)$ & $5(<1 \%)$ \\
\hline
\end{tabular}

Data are presented as count $(\%)$

Due to potential association of several molecules within one aerosol, percentages may sum up exceeding $100 \%$. For each therapeutic class, the number of aerosol administrations including at least one drug of the considered class is indicated; the corresponding percentage represents the proportion within all administrations. Similarly at the molecule level, the number of administrations including this molecule is indicated; the

supplement Table 6) [5-17]. Regarding safety, the predominant use of nebulizers to deliver bronchodilators and corticosteroids in ventilated patients seems intriguing, as they are available as MDIs. In fact, as aerosols were predominantly delivered using jet nebulizers, with breathactuated ventilator integrated systems frequently unavailable, about every fourth aerosol administration exposed intubated patients to uncontrolled tidal volumes (the jet nebulizer being supplied by an external gas source) [27]. The use of MDIs, when available, might be preferred. Actually, only about $9 \%$ of bronchodilator and/or corticosteroids aerosols in intubated patients were delivered with a MDI connected to an inhalation chamber, whereas this simple technique is the one with the most extensively evaluated efficacy [5-13]. The second important safety issue relates to particles cleared through the expiratory limb, which may interfere with the proper function of the ventilator expiratory block, particularly when nebulizing antibiotics or performing continuous nebulization [10]. One-third of aerosols $(n=1502)$ were administered in intubated patients with no filter protecting the expiratory block. No dysfunction was documented over the 2-week study period, in part due to the corresponding percentage represents the proportion within the therapeutic class. Numbers of patients refer to patients having received at least one aerosol of the considered class or molecule; percentages were calculated relative to all patients and within each therapeutic class

a $0.9 \%$ sodium chloride was not considered when being used as a solvent for another molecule

predominant delivery of bronchodilators and corticosteroids; nevertheless, given the very severe complications reported, including pneumothorax and cardiac arrest, additional educational efforts are warranted in order to promote better practice [10, 14, 28-30].

Regarding efficacy, unlike for bronchodilator therapy, nebulization/ventilation set-up is a key factor for success of inhaled anti-infectious therapy, in particular when aiming to treat pneumonia, which was the case for $73 \%$ of anti-infective aerosol deliveries [31]. Indeed, delivering inhaled antibiotics to the infected, poorly aerated, distal alveolar compartment of intubated patients may be challenging [32]. In this regard, jet nebulizer, the most frequently used type of nebulizer for antibiotic administration, is well known for a high residual volume (amount of drug which remains in the nebulizer at the end of nebulization) as compared to vibrating mesh and ultrasonic nebulizers [6]. This may influence aerosol therapy efficacy. Lu et al. observed that nebulizing $400 \mathrm{mg}$ of colistimethate using a mesh nebulizer enabled the treatment of nosocomial pneumonia, while the same dose placed in a jet nebulizer results in a much lower dose of drug actually deposited in the patient [14]. Similarly, 
Palmer et al. reported positive results nebulizing aminoglycosides and/or vancomycin using a breath-actuated jet nebulizer in patients suffering nosocomial tracheobronchitis or pneumonia $[16,17]$. Again, the common practice observed in the present study, consisting in placing the nebulizer at the Y piece (Fig. 1), may be counterproductive by favoring aerosol loss in the expiratory limb and preventing the replication of favorable results in daily clinical practice [14-17, 27, 33]. Such dose/nebulizer issues may, in part, explain some discrepancies among studies evaluating the potential benefit of inhaled antibiotics to treat multidrug-resistant lung infections [34]. Furthermore, unlike in the aforementioned prospective interventional studies, ventilator settings were left unchanged and heated humidifiers kept active during, respectively, 70 and $40 \%$ of anti-infectious aerosols recorded [14-17].

While anti-infective aerosols concerned a limited number of patients $(1 \%)$, bronchodilators and corticosteroids were extensively delivered (every fifth critically ill patient). Beyond bronchodilation, unlike in the outpatient setting, no long-term patient-centered outcomes have been evaluated in critically ill patients [2, 3, 5-13, 35]. Given potential side effects, one may question the value of their large use, far beyond the population of patients receiving it at home and with obstructive pulmonary disease, with indications such as infections which may need specific evaluation [36].

\section{Study limits}

Beyond capturing only a low incidence of side effects not defined a priori, which may be underestimated, the study design restricting observation on two consecutive weeks did not enable the capture of seasonal variations in practice. Aerosol therapy may be more frequent in the winter months due to increased respiratory infections. Albeit including a high number of centers in several countries on all continents, the international scope of the study was damped by the predominance of European centers, especially in France and Spain, and by the absence of North American centers. Thus, results cannot be extrapolated worldwide. Interestingly, some practice heterogeneity was observed (see electronic supplement Table 4) calling for additional evaluation in regions not covered by the present work. Specific case mix within each center, not captured by the present study, may in part explain the observed aerosol therapy practices. Centers participated in the study on a voluntary basis, and one cannot exclude a bias towards more experienced or expert units, physicians' knowledge being not assessed in this study. As aerosol efficacy was not evaluated in the present study, observed practice can only be put into perspective with existing knowledge and recommendations, without drawing conclusions about the efficacy of aerosol therapy in individual patients. Similarly, staff protection from potential aerosol toxicity and the types of NIV interfaces were not recorded in this study. Finally, given the noninterventional design, one cannot exclude that the study by itself induced some changes in aerosol therapy practice during the observation period.

\section{Conclusions}

Aerosol therapy is a common practice concerning a fifth to a quarter of intensive care and intermediate care patients despite the lack of proven benefit on patients centered outcome. The frequent implementation of aerosol therapy during invasive artificial ventilation seemed suboptimal in a significant number of cases and almost never performed during NIV, calling for actions on the educational level such as issuing guidelines specifically dedicated to aerosol therapy in critically ill patients.

Acknowledgments The authors acknowledge receipt of grant ANR-2010 BLAN 111905 from Agence Nationale de la Recherche. Beyond the investigators listed below, the authors sincerely thank all physicians, nursing and research staff who participated in the study.

List of investigators/contributors of the participating centers: all contributors actively participated in patient inclusions and data acquisition.

Hasania Abdel-Hadi, Ciudad Real, Spain; Eduardo AguilarAlonso, Cabra, Spain; Hernan Aguirre-Bermeo, Reus, Spain; Türkay Akbaş, Istanbul, Turkey; Rogelio Anchorena-Gonzalez, Catan, Argentina; Nelson Antunes, Castelo Branco, Portugal; Julio Apodaca, Asunción, Paraguay; Laurent Argaud, Lyon, France; JeanMichel Arnal, Toulon, France; Donaldo Arteta, Sevilla, Spain; Aurélie Aubrey, Tours, France; Hilario Badiola-Villa, Safra, Spain; Guillaume Barberet, Mulhouse, France; Thomas Bauer, Krems, Austria; Patrice Befort, Montauban, France; Vladislav Belskiy, Nizhniy Novgorod, Russia; Abdellatif Benslama, Casablanca Morocco; Philippe Berger, Chalons-en-Champagne, France; Philippe Berger, Perpignan, France; Jean Bergounioux, Paris, France; Pascal Beuret, Roanne, France; Hugo Bianco, Asuncion, Paraguay; Vanessa Bironneau, Poitiers, France; Maria-Maddalena Bitondo, Trento, Italy; Alice Blet, Paris, France; Laetitia Bodet-Contentin, Paris, France; Charra Boubaker, Casablanca, Morocco; Sandrina Bouhon, Yvoir, Belgium; Thierry Boulain, Orléans, France; Pierre Bulpa, Yvoir, Belgium; Gustavo-Armando Carrasco, Resistencia, Argentina; Diego Castanares-Zapatero, Brussels, Belgium; Cristian Cesio, Buenos Aires, Argentina; Qi Chen, Hangshou, China; Paulo Costa, Castelo Branco, Portugal; Emilio Curiel-Balsera, Malaga, Spain; Ivan Daroui, Verona, Italy; Julian de Capadocia-Rosell, Albacete, Spain; Adriana Delgado-Bravo, Ibarra, Ecuador; Jean Dellamonica, Nice, France; Arnaud Desachy, Angoulême, France; Alexis Donzeau, Angers, France; Ying Duan, Xian Yang, China; Jonathan Dugernier, Brussels, Belgium; Hervé Dupont, Amiens, France; Antoine Duwat, Amiens, France; Antoine Edelson, Pirae, French Polynesia; Stephan Ehrmann, Tours, France; Mohammad Faheem, Mullingar, Ireland; Paula Fernandez-Ugidos, Ourense, Spain; Ricard Ferrer Roca, Terrassa, Spain; Jean-Pierre Frat, Poitiers, France; Marc Gainnier, Marseille, France; Alexandre Gamelin, Lille, France; Horacio Garcia-Delgado, Sevilla, Spain; Vincent Gardan, Toulon, France; Mirian Gimeno, Albacete, Spain; Oscar Gomez-Aduviri, Lima, Peru; Olinda Goncalve, Castelo Branco, Portugal; David Gu, Paris, France; Jose Gutierrez-Rubio, 
Albacete, Spain; Caroline Haggenmacher, Brussels, Belgium; Ni Haibin, Nanjing, China; Ezzouine Hanane, Casablanca, Morocco; Sarah Heili Frades, Madrid, Spain; Serge Heines, Maastricht, Netherlands; Yang Hilin, Shanghai, China; Christophe Huet, Pirae, French Polynesia; Dominique Hurel, Mantes la Jolie, France; Stefano Italiano, Tortosa, Spain; Amira Jammoussi, Ariana, Tunisia; Claire Jannel, Grenoble, France; Juan Jimenez-Delgado, Don Benito, Spain; Sebastien Jochmans, Melun, France; Bernard Just, Charleville-Mezière, France; Sait Karakurt, Istamuljeu, Turkey; Blahut Ladislav, Olomouc, Czech Republic; Lucas Lage-Cendon, Vigo, Spain; Karim Lakhal, Nantes, France; Gu Lei, Shanghai, China; Héctor León Yoshido, Lima, Peru; Dalfino Lidia, Bari, Italy; Francisco Lobato-Madueno, Marbella, Spain; Carlos Lopes, Lisboa, Portugal; Jesus Lopez-Herce, Madrid, Spain; Luis LopezLachira, Lima, Peru; Qin Lu, Paris, France; Christine Mabilat, Tours, France; Khalil Magdy, Cairo, Egypt; Tomas Mallor-Bonet, Huesca, Spain; Antoine Marchalot, Rouen, France; Setten Mariano, Buenos Aires, Argentina; Philippe Mateu, Charleville-Mezières, France; Roberto Mendes, Castelo Branco, Portugal; Jonathan Messika, Colombes, France; Fernando Micaelo, Castelo Branco, Portugal; Francisco Millan-Castilla, Malaga, Spain; Besbes Mohamed, Ariana, Tunisia; Esperanza Molero, Madrid, Spain; Omar Montes-de Oca, Montevideo, Uruguay; Guillermo Mora, Guanajuato, Mexico; Grégoire Muller, Orléans, France; Stefano Nava, Bologna, Italy; Jasmine Naveen, Trivandrum, India; Metaxia Papanikolaou, Athens, Greece; Francisco-Jose Parrilla, Barcelona, Spain; Anthony Parsons, Croydon, United Kingdom; Rina Patel, Ahmedabad, India; Valerie Payen, Grenoble, France; Miguel Pereira-Loureiro, Vigo, Spain; Olatz Perez-Aizcorreta, Palma de Mallorca, Spain; Manuel Perez Marquez, Madrid, Spain; Lise Piquilloud, Angers, France; Dcosta Pradeep, Pune, India; Gan
Quan, Wuhan, China; Belen Quesada-Bellver, Mostoles, Madrid, Spain; Satti Rami, Dubai, United Arab Emirates; Keyvan Razazi, Créteil, France; Gemma Rialp, Palma de Mallorca, Spain; JeanPhilippe Rigaud, Dieppe, France; Ferran Roche-Campo, Tortosa, Spain; Amalo Romnee, Yvoir, Belgium; Assumpta Rovira, L'hospitalet de Llobregat, Spain; Jose Sanchez-Garcia, Queretaro, Mexico; Jose-Manuel Sanson, Santa Rosa, Argentina; Laura Sayagues, Lugo, Spain; Véronique Simeon Vieules, Tours, France; Slobodan Spasojevic, Novi Sad, Serbia; Mohammed Ibrahim Syed Mohamed, Madurai, India; David Thévoz, Lausanne, Switzerland; Arnaud W Thille, Poitiers, France; Daniel Kuezina Tonduangu, Sens, France; Josep Trenado-Alvarez, Terrassa, Spain; Joao Valente, Castelo Branco, Portugal; François Vermeulen, Geneva, Switzerland; Carlos Vicent, Xativa, Spain; Fu Xiaoyun, Zunyi, China; Begona Zalba-Etayo, Zaragoza, Spain; Xin Zhang, Hangzhou, China; Shongheng Zhang, Jinhua, China; Feng Zhu, Nanchang, China; Elie Zogheib, Amiens, France.

\section{Compliance with ethical standards}

Conflicts of interest S.E.'s institution received research equipment and/or research funding from: Aerogen, Galway, Ireland; Axess Vision Technology, Tours, France; Fisher \& Paykel, Auckland, New Zealand; La diffusion technique française, Saint-Etienne, France; Penn-Century Inc., Wyndmoor, USA; none was related to this particular study. L.B.'s laboratory received research grants from Covidien, Dräger, Vygon, Philips Respironics and GE Healthcare; none was related to this particular study. All other authors declare no conflict of interest.

\section{References}

1. Dolovich MB, Dhand R (2011) Aerosol drug delivery: developments in device design and clinical use. Lancet 377:1032-1045

2. Global Initiative for Chronic Obstructive Lung Disease (GOLD) (2014) Global strategy for the diagnosis, management and prevention of COPD. http://www.goldcopd.org/. Accessed 27 July 2015

3. Global Initiative for Asthma (GINA) (2014) Global strategy for asthma management and prevention. http://www.ginasthma.org/. Accessed 27 July 2015

4. Mogayzl PJ, Naureckas ET, Robinson KA, Mueller G, Hadjiliadis D, Hoag JB, Lubsch L, Hazle L, Sabadosa K, Marshall B, Committee Pulmonary Clinical Practice Guidelines (2013) Cystic fibrosis pulmonary guidelines. Chronic medications for maintenance of lung health. Am J Respir Crit Care Med 187:680-689

5. O'Doherty MJ, Thomas SH (1997) Nebuliser therapy in the intensive care unit. Thorax 52:S56-S59
6. Ari A, Fink JB, Dhand R (2012) Inhalation therapy in patients receiving mechanical ventilation: an update. J Aerosol Med Pulm Drug Deliv 25:319-332

7. Vecellio L, Guérin C, Grimbert D, De Monte M, Diot P (2005) In vitro study and semiempirical model for aerosol delivery control during mechanical ventilation. Intensive Care Med 31:871-876

8. Diot P, Morra L, Smaldone GC (1995) Albuterol delivery in a model of mechanical ventilation. Comparison of metered-dose inhaler and nebulizer efficiency. Am J Respir Crit Care Med 152:1391-1394

9. Miller DD, Amin MM, Palmer LB, Shah AR, Smaldone GC (2003) Aerosol delivery and modern mechanical ventilation: in vitro/in vivo evaluation. Am J Respir Crit Care Med 168:1205-1209

10. Mojoli F, Iotti GA, Imberti R, Braschi A (2013) The importance of protecting the mechanical ventilator during colistin methanesulfonate nebulization. Intensive Care Med 39:535-536
11. Laube BL, Janssens HM, de Jongh FHC, Devadason SG, Dhand R, Diot P, Everard ML, Horvath I, Navalesi P, Voshaar T, Chrystyn H (2011) What the pulmonary specialist should know about the new inhalation therapies. Eur Respir J 37:1308-1331

12. Mancebo J, Amaro P, Lorino $\mathrm{H}$, Lemaire F, Harf A, Brochard L (1991) Effects of albuterol inhalation on the work of breathing during weaning from mechanical ventilation. Am Rev Respir Dis 144:95-100

13. Mouloudi E, Prinianakis G, Kondili E, Georgopoulos D (2001) Effect of inspiratory flow rate on beta2-agonist induced bronchodilation in mechanically ventilated COPD patients. Intensive Care Med 27:42-46

14. Lu Q, Yang J, Liu Z, Gutierrez C, Aymard G, Rouby JJ (2011) Nebulized ceftazidime and amikacin in ventilatorassociated pneumonia caused by Pseudomonas aeruginosa. Am J Respir Crit Care Med 184:106-115 
15. Lu Q, Luo R, Bodin L, Yang J, Zahr N, Aubry A, Golmard JL, Rouby JJ (2012) Efficacy of high-dose nebulized colistin in ventilator-associated pneumonia caused by multidrug-resistant Pseudomonas aerugiosa and Acinetobacter baumannii. Anesthesiology 117:1335-1347

16. Palmer LB, Smaldone GC, Chen JJ, Baram D, Duan T, Monteforte M, Varela M, Tempone AK, O'Riordan T, Daroowalla F, Richman P (2008) Aerosolized antibiotics and ventilatorassociated tracheobronchitis in the intensive care unit. Crit Care Med 36:2008-2013

17. Palmer LB, Smaldone GC (2014) Reduction of bacterial resistance with inhaled antibiotics in the intensive care unit. Am J Respir Crit Care Med 189:1225-1233

18. Esteban A, Ferguson ND, Meade MO, Frutos-Vivar F, Apezteguia C, Brochard L, Raymondos K, Nin N, Hurtado J, Tomicic V, Gonzalez M, Elizalde J, Nightingale P, Abroug F, Pelosi P, Arabi Y, Moreno R, Jibaja M, D'Empaire G, Sandi F, Matamis D, Montanez AM, Anzueto A, VENTILA Group (2008) Evolution of mechanical ventilation in response to clinical research. Am J Respir Crit Car Med 177:170-177

19. Esteban A, Frutos-Vivar F, Muriel A, Ferguson ND, Penuelas O, Abraira V, Raymondos K, Rios F, Nin N, Apezteguia C, Violi DA, Thille AW, Brochard L, Gonzalez M, Villagomez AJ, Hurtado J, Davies AR, Du B, Maggiore SM, Belosi P, Soto L,

Tomicic V, D'Empaire G, Matamis D, Abroug F, Moreno RP, Soares MA, Arabi Y, Sandi F, Jibaja M, Amin P, Koh Y, Kuiper MA, Bülow HH, Zeggwagh AA, Anzueto A (2013) Evolution of mortality over time in patients receiving mechanical ventilation. Am J Respir Crit Care Med 188:220-230
20. Ehrmann S, Roche-Campo F, Sferrazza Papa GF, Isabey D, Brochard L, ApiouSbirlea G, Reva Research Network (2013) Aerosol therapy during mechanical ventilation: an international survey. Intensive Care Med 39:1048-1056

21. Grivans C, Lindgren S, Aneman A, Stengwist O, Lundin S (2009) A Scandinavian survey of drug administration through inhalation, suctioning and recruitment maneuvers in mechanically ventilated patients. Acta Anaesthesiol Scand 53:710-716

22. Le Gall JR, Lemeshow S, Saulnier F (1993) A New Simplified Acute Physiology Score (SAPS II) Based on a European/North American Multicenter Study. JAMA 270:2957-2963

23. Fauroux B, Jtti E, Pigeot J, Isabey D, Meignan M, Ferry G, Lofaso F, Willemot JM, Clément A, Harf A (2000) Optimization of aerosol deposition by pressure support in children with cystic fibrosis: an experimental and clinical study. Am J Respir Crit Care Med 162:2265-2271

24. Nava S, Karakurt S, Rampulla C, Braschi A, Fanfulla F (2001) Salbutamol delivery during noninvasive mechanical ventilation in patients with chronic obstructive pulmonary disease: a randomized, controlled study. Intensive Care Med 27:1627-1635

25. Galindo-Filho VC, Brandao DC, Ferreira RC, Menezes MJ, AmeidaFilho P, Parreira VF, Silva TN, Rodrigues-Machado MG, Dean E, Dornelas de Andrade A (2013) Non invasive ventilation coupled with nebulization during asthma crises: a randomized controlled trial. Respir Care 58:241-249

26. Hess DR (2015) Aerosol therapy during noninvasive ventilation or high-flow nasal cannula. Respir Care 60:880-893

27. Ehrmann S, Lyazidi A, Louis B, Isabey D, Le Pennec D, Brochard L, ApiouSbirlea G (2014) Ventilator-integrated jet nebulization systems: tidal volume control and efficiency of synchronization. Respir Care 59:1508-1516
28. Kiatboonsri S, Kiatboonsri C, Theerawit P (2010) Fatal respiratory events caused by zanamivir nebulization. Clin Infect Dis 50:620

29. Davies JB, Bromilow J (2011) Bacterial filter obstruction with the use of ultrasonic nebulisation. Anaesthesia 66:394-395

30. Tonnelier A, Lellouche F, Bouchard PA, L'Her E (2013) Impact of humidification and nebulization during expiratory limb protection: an experimental bench study. Respir Care 58:1315-1322

31. Rouby JJ, Bouhemad B, Monsel A, Brisson $\mathrm{H}$, Arbelot $\mathrm{C}$, Lu Q, the Nebulized Antibiotics Study Group (2012) Aerosolized antibiotics for ventilator-associated pneumonia: lessons from experimental studies. Anesthesiology 117:1364-1380

32. Elman M, Goldstein I, Marquett $\mathrm{CH}$, Wallet F, Lenaour G, Rouby JJ, Experimental ICU Study Group (2002) Influence of lung aeration on pulmonary concentrations of nebulized and intravenous amikacin in ventilated piglets with severe bronchopneumonia. Anesthesiology 97:199-206

33. Palmer LB, Smaldone GC, Simon SR, O'Riordan TG, Cuccia A (1998) Aerosolized antibiotics in mechanically ventilated patients: delivery and response. Crit Care Med 26:31-39

34. Valachis A, Samonis G, Kofteridis DP (2015) The role of aerosolized colistin in the treatment of ventilator-associated pneumonia: a systematic review and metaanalysis. Crit Care Med 43:527-533

35. Nava S, Compagnoni ML (2000) Controlled short-term trial of fluticasone propionate in ventilatordependent patients with COPD. Chest 118:990-999

36. Jaillette E, Nseir S (2011) Relationship between inhaled $\beta_{2}$-agonists and ventilator-associated pneumonia: a cohort study. Crit Care Med 39:725-730 